\title{
The Voces Project: \\ Investigating How Latino/a Immigrant Children Make Sense of Engaging in School and School Mathematics
}

\author{
John C. Knudson-Martin \\ Eastern Oregon University
}

U. S. A.

This study investigates how a group of Mexican immigrant children in the United States made sense of engaging in school and school mathematics. The research focused on a population of Latino/a middle school students who were a distinct minority, building a model that shows how a complex set of cognitive, sociocultural, and institutional factors mediated these students' engagement and success in school. The results of this research will help educators understand the complex social environment that faces immigrant children and impacts their performance and engagement in school and school mathematics.

\author{
Theoretical Framework \\ Methodology \\ The Voces Model \\ Summary of Influences on Engagement in School \\ Conclusion: Implications for Research and Schools \\ Notes \\ References
}

When asked, "What does it take to be good in math?" Oscar, a 14-year-old Mexican immigrant boy, answered, "What does it take? It takes heart." Heart and a willingness to keep trying or "Si, se puede" were two of the major assets that immigrant Latino/a children and their parents consistently presented when discussing their lives as members of a community in the Pacific Northwest of the United States. These assets represent part of the funds of knowledge that these children bring with them to school (Gonzalez, Moll, \& Amanti, 2005). This study investigates how Mexican immigrant children attending a predominantly White middle school in the United States made sense of engaging in school and school mathematics and how their familial and cultural backgrounds interacted with the school culture and expectations. Multiple studies have examined the factors that influence Latino student engagement in schools that serve populations that are predominantly Latino/a (e.g., Gutierrez, 2002b; Gutstein, Lipman, Hernandez, \& de los Reyes, 1997; Moll, 1997). This research focuses on a population of Latino students who form a distinct minority. The populations of countries throughout the world are becoming more diverse, and this diversity is becoming more widespread (Gandara \& Contreras, 2009). Schools worldwide are now grappling with how to serve an increasingly diverse population of students. The results of this research will help educators understand how minority status combines with sociohistorical, community, 
school, and institutional influences to impact Latino/a student performance and engagement with school and school mathematics. It will provide information that will help educators develop school and mathematics programs that more equitably serve all students.

The reader will find few "mathematical issues" in this study. The original focus of this research was to examine the issues that caused students to struggle with engaging in middle school mathematics classes. Approximately half the scripted questions used in the interviews conducted for this research asked about engaging in school mathematics. Students, parents, teachers, and counselors consistently answered those questions without referring to the mathematics that was being taught. What the participants made clear by their responses was that the important issues involved in engaging with school and school mathematics had to do with the larger context in which the students and the school operated. As will be shown, curriculum and language affected student performance, but culture, social interactions, and institutional policies had profound effects on how these students made sense of engaging in school and school mathematics.

\section{Theoretical Framework}

Motivation is the process by which students become engaged in school activities and programs (Bandura, 1997; Eccles \& Wigfield, 2002; Knudson-Martin, 2011; Maehr, 1984; Murphy \& Alexander, 2000; Zimmerman, Bandura, \& Martinez-Pons, 1992). Social factors, such as the child's culture, family, and peer relationships (e.g., Boaler, 2000; Hickey \& Granade, 2004; Valadez, 2008), and individual factors, such as student interests, goals and beliefs (e.g., Covington, 1992; Dewey, 1913; Pajares \& Graham, 1999) have both been shown to influence the process of becoming motivated. These factors do not operate separate from the social context within which the students live. To build a model for understanding and explaining how immigrant children make sense of engaging in school and school mathematics, this study uses a theoretical framework that combines the individual cognition tradition that is prominent in psychological literature on motivation and learning (e.g., Bandura, 1997; Deci \& Ryan, 2002; Donovan \& Bransford, 2005) with the sociocultural view that learning and developing motivation occur primarily in a social context (e.g., Boaler, 1999; Cobb, 1994; Vygotsky, 1986). Both of these approaches to understanding the process of student motivation provide valuable insights into how students engage in school. Setting this study in a theoretical framework that combines these two views facilitates the development of an understanding of how student motivation and learning operate within a social context. Wertsch and Toma (1995) in their book chapter, "Discourse and Learning in the Classroom: A Sociocultural Approach," discussed the type of theoretical framework that is needed in studies of learning in schools. They state:

One of the reasons for the weak theoretical underpinnings in this area is that focusing on the social constitution of mental functioning requires us to cross disciplinary boundaries. Instead of viewing this as a barrier, however, we believe that it is an opportunity. It is an opportunity to integrate methods and bodies of knowledge that have been artificially separated by disciplinary boundaries, and it 
is an opportunity we cannot ignore if we are to be serious about how theory and practice in education can inform one another. (p. 159)

\section{A Sociocultural Model for Minority Student School Engagement}

In his study of African American middle school students and their motivation to engage in school mathematics, Martin (2000) proposed that a student's motivation to engage in school is impacted by the students' sociohistorical backgrounds, the influences of their local community, and the culture and structure of their school (Figure 1). The sociohistorical backgrounds of a people are the stories they hold in common about how history has shaped and brought them to where they are now. The influences of the local community include factors within the children's social community (family, friends, and their status within larger community). The culture and structure of the school include the cultural orientation of the school and the impact that orientation has on its organization. In this model, Martin proposed that individual cognitive processes happen within this social context and that these three areas of the students' social world all mediate, but do not control, the extent to which students engage in school and school mathematics. Martin's model values both individual cognitive processes and the social context in which they occur. This model for understanding individual student motivation within a social context was used in the present study as a starting point for analyzing how Latino/a students make sense of engaging in school and school mathematics. This understanding will also be informed by the work of Valenzuela (1999) and Delpit (1992) who frame immigrant engagement in school as requiring programs and faculty that intentionally recognize and honor immigrant student cultures.

Figure 1. Model of the sociohistorical, community, and school mediating influences on student engagement and motivation in school (Martin, 2000)

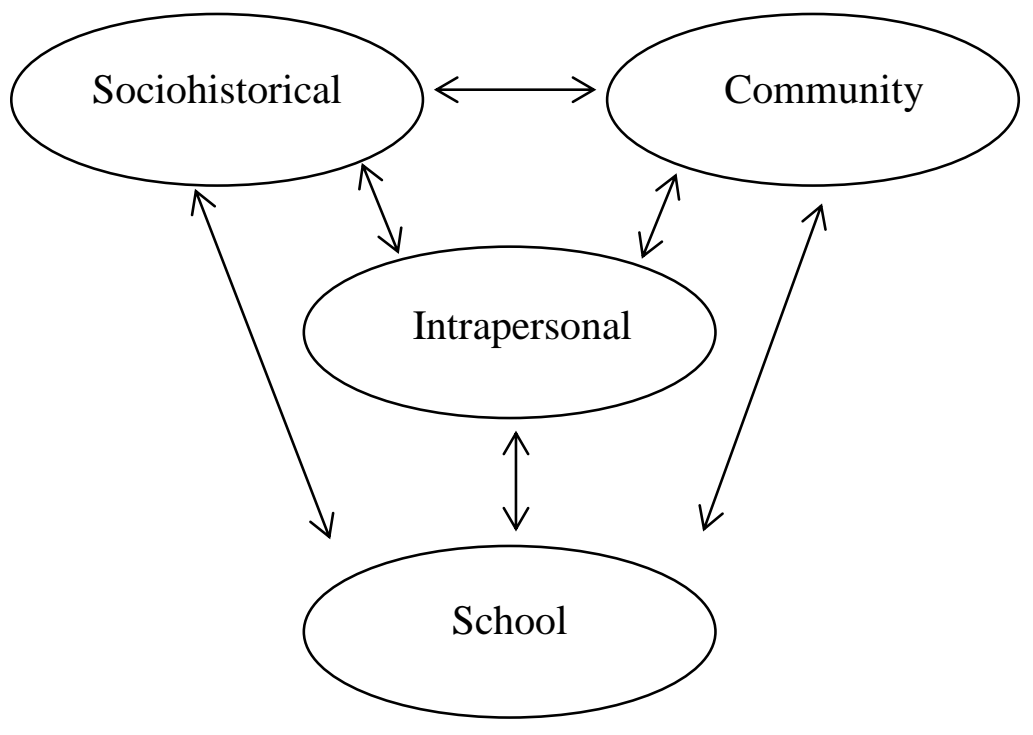




\section{Methodology}

\section{Research Question}

The purpose of this study was to develop a description and model for understanding and explaining how Latino/a immigrant students make sense of engaging in school and school mathematics. To serve this purpose within the cross-disciplinary theoretical framework described above, this study was guided by the following research question:

How do sociohistorical backgrounds, community forces, and school structure and culture mediate Latino/a students' motivation and engagement in school and school mathematics?

\section{Study School and Participants}

This research was conducted at Valley Middle School, ${ }^{1}$ a $6^{\text {th }}-8^{\text {th }}$ grade school located in a medium-sized community (population 55,000) in an agricultural area of the Pacific Northwest of the United States. The community's two largest employers are a state university and a large computer technology corporation. There were approximately 620 students enrolled at Valley Middle School at the time of the study, and the ethnic make-up of the student body was $78 \%$ Caucasian, 18\% Latino/a, 3\% Asian American, and $1 \%$ other. Twenty-seven percent of the students at Valley Middle School were eligible for free and reduced lunches (low income students). The faculty of the school was $95 \%$ Caucasian of European descent, while multiple office personnel and instructional aides were Hispanic and native Spanish speakers. The school provides an English Language Learner program for the Latino/a students, and the school has been designated within the district as the magnet middle school for English learners of Hispanic descent. There are two middle schools in the community. Because of the magnet school designation, all of the Mexican immigrant children in the town attend Valley Middle School. Two counselors are employed by the school; both understand Spanish, and one is a native speaker.

The Latino/a students in the school were essentially all of Mexican descent, and all of the students that participated in the Voces study were Mexican immigrants. The large majority of the parents of these students worked in low paying jobs in the agriculture, construction or service industry. Approximately $50 \%$ students participating in the study were undocumented and in the United States illegally. Approximately $80 \%$ of their parents were undocumented.

\section{Interviews}

To collect data to address this study's research question, group interviews were conducted with Latino/a students, their parents and family members, and school personnel. Students participating in the interviews were members of the Voces Club, a school organization started by the school's counselors to give the Mexican immigrant children a place to talk about their experiences in the school and community, and a way of connecting to the school. Voces club meetings and all interviews were conducted in 
English. Questions were occasionally translated into Spanish when students did not understand the wording or context of the question. Parents and adult family members of Voces students were the participants in the parent interviews. These interviews occurred after pizza dinners at the school, were conducted in Spanish, and were led by the native Spanish-speaking school counselor. Many of the parents brought younger children to the parent night. Most families seemed to have multiple young children. Separate group interviews were conducted with the math faculty and the bilingual aides to gain an understanding of the school personnel's perspective on Latino/a student participation in school and school mathematics. A script of questions was used in each interview to initiate discussions with and among the participants (see Table 1). These questions were developed out of a discussion between the researcher and the two school counselors. This discussion centered on what was seen as the major issues impacting student and family engagement in the school, and the questions were meant to draw out a discussion of these issues. The questions were used as a guide for the interviews; the script was not followed precisely. Additional questions were asked based on the direction of the responses of the interviewees, and some questions were omitted when they did not fit with the flow of the conversations.

\begin{tabular}{|c|c|c|}
\hline $\begin{array}{l}\text { Student } \\
\text { School interests and activities } \\
\text { Easy and hard aspects of } \\
\text { school } \\
\text { Goals for school, college, and } \\
\text { careers } \\
\text { Interests and goals in math } \\
\text { Homework } \\
\text { School programs and support } \\
\text { Teachers and school personnel } \\
\text { Relationships and friendships } \\
\text { with Latinos and non-Latinos } \\
\text { Mexican schools and } \\
\text { communities } \\
\text { Language and school } \\
\text { Immigration concerns } \\
\text { Advantage and disadvantages } \\
\text { of being Latino } \\
\text { Examples of support and } \\
\text { prejudice }\end{array}$ & $\begin{array}{l}\text { Parents } \\
\text { Best part of school for your } \\
\text { children } \\
\text { Hardest part of school for your } \\
\text { children } \\
\text { Parents' own experiences with } \\
\text { school } \\
\text { Treatment by school and } \\
\text { community } \\
\text { Math tracking } \\
\text { Goals for children in school and } \\
\text { math } \\
\text { Career goals for children } \\
\text { Mexican schools } \\
\text { Immigration } \\
\text { School support }\end{array}$ & $\begin{array}{l}\text { Teachers and Aides } \\
\text { Knowledge of Latino student } \\
\text { backgrounds } \\
\text { Student cliques and social } \\
\text { groups } \\
\text { Strengths and weaknesses of } \\
\text { Latino students } \\
\text { Challenges of teaching Latinos } \\
\text { Language issues } \\
\text { Perceptions of math readiness } \\
\text { among Latino students } \\
\text { Student goals and interests in } \\
\text { math } \\
\text { Grouping in classes } \\
\text { Teachers' needs for helping } \\
\text { Latino students } \\
\text { Communication with families }\end{array}$ \\
\hline
\end{tabular}




\section{Data Analysis}

All interviews were audio-recorded and the recordings were transcribed. An English translation of the parent interview was audio-recorded, and this translation was then transcribed. Transcripts of the interviews were coded and analyzed using a grounded theory methodology as described by Charmaz (2006). After the initial analysis, the description and model emerging from the data were presented to a group of student participants and to the school counselors for their critique and analysis.

\section{The Voces Model}

The description and model that emerged from this data analysis contains five different categories: the Sociohistorical and Community categories used by Martin (2000), two school categories (School Affordances and School Constraints), and a fifth category titled Prejudice and Institutional Bias. The fifth category describes those relational and governmental influences that kept the Latino/a students and parents from feeling that they legitimately belonged to and could engage in the life of the school and local community. These five categories provide the framework for The Voces Model (see Figure 2). The section below discusses the five categories of this model and explains how this population of Latino/a students made sense of engaging in school and school mathematics.

\section{Sociohistorical: Heart - Sí, Se Puede}

Ethic and models of hard work. Oscar's assertion that "it's heart" that is needed to be good at mathematics in school was indicative of his fellow students' beliefs and the parents' commitment to hard work. It was also reflective of the funds of knowledge and beliefs that come from these students' cultural background (Gonzalez, et al., 2005). This theme came up repeatedly in the student and parent interviews. In the following excerpt, the $8^{\text {th }}$ grade girls discuss the value of hard work:

Interviewer: Is it more important to be smart or hardworking?

Many girls together: Hardworking.

Yvette: Umm, it would be hardworking. Because if you were smart and you didn't work hard, then what's the point?

The girls' views of hard work were reflective of comments made by their parents. In the following excerpt from the parent interview, Chiara, a mother of two students at Valley Middle School, encourages and reminds her fellow parents about the value of hard work.

Chiara: Whether it is in the fields or in the kitchen or wherever we work, we are the example. What better way of showing your kids what to do than showing what effort you are putting forward to get ahead. For us, it's a little more difficult because of the language. Because of the papers. We are fighting hard and you may not believe this, but they are watching your struggle. 
Figure 2. The Voces Model. Factors that Mediate How Latino/a Middle School Students Make Sense of Engaging in School and School Mathematics.

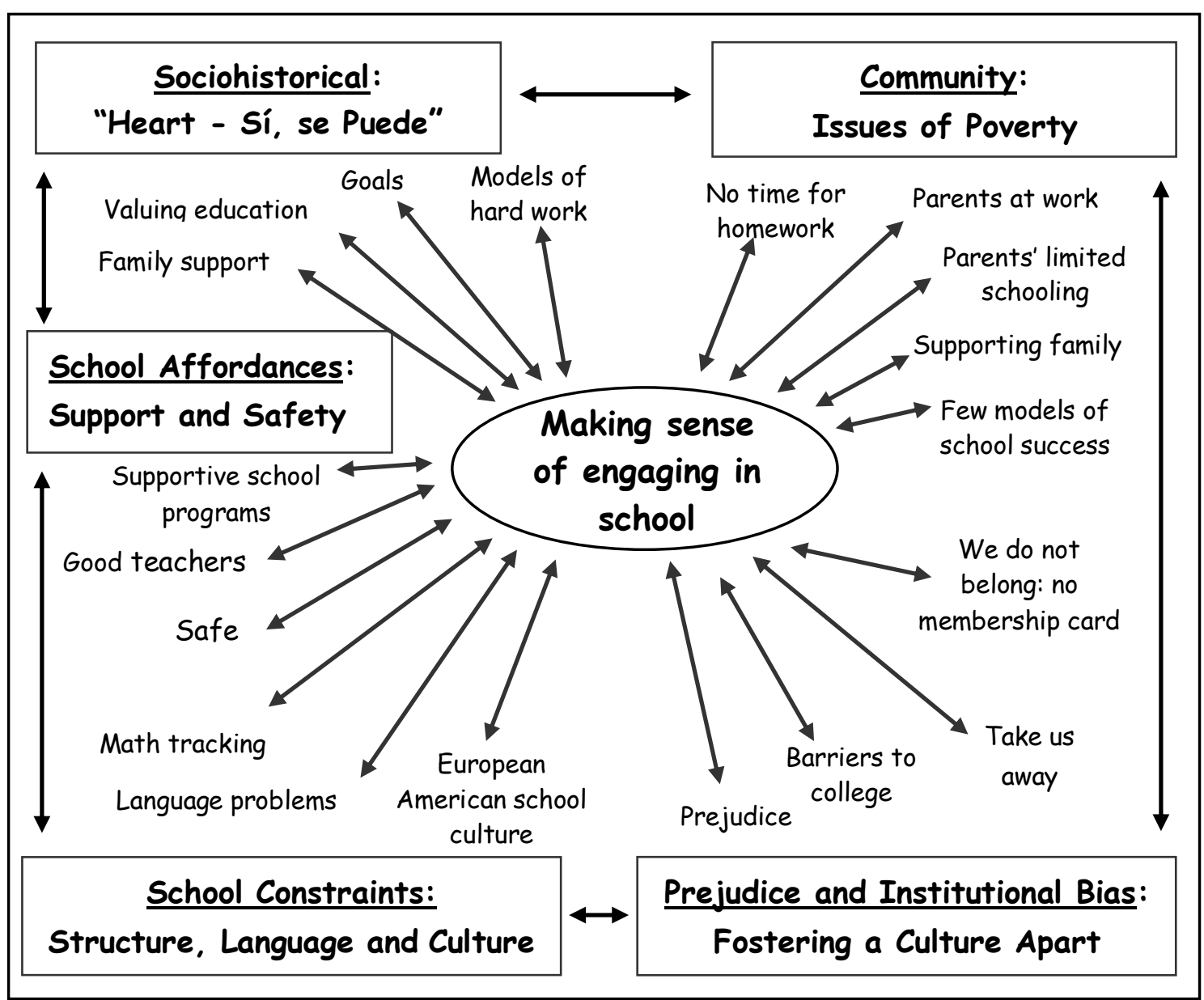

Setting goals for school. The students understood their being in the United States in terms of the opportunities it made available to them. In talking about some of the problems they had in school, the $8^{\text {th }}$ grade boys discussed why their parents had brought them to the United States:

Mateo: What keeps me up and keeps me going is my Mom 'cause she brought me here so I can go to college and so I can help her out when she can't work anymore.

Oscar: Our parents brought us here for the good futures that we have that they didn't have.

\section{School Affordances: Support and Safety}

Supportive school programs and teachers. Valley Middle School has invested in supporting the language needs of their Latino/a students. In the excerpt below, Anna $\left(8^{\text {th }}\right.$ grader $)$ discusses how the support she receives has helped her in science class. 
Anna: Yeah, 'cause of like, in my science class, I have a teacher (a teacher $\overline{\text { aide) }}$ that she speaks Spanish, Ms. Z., and like that's why science is not that hard 'cause like when the teacher explains something, like then Ms. Z. comes and explains to us in Spanish so I like get things better.

Spanish-speaking aides are placed in classes with Latino/a students who need language help; daily English language learner classes are offered for Latino/a students who are not fluent in English.

Safe school environment. Parents and children reported that Valley Middle School was relatively free of violence. There is very little gang activity in the schools and few violent conflicts between students. Clara, in discussing her three children's experiences in the schools, stated that "the reason they like the schools in Valley City is because they're good and they're calm." Rebecca, an eighth grader who moved to Valley City from California, reported the following:

Rebecca: Well, in California, like you could see some like in high school or something you could see people beating up other people and then right here in Valley City you don't see so much violence.

The school provides these Latino/a children with a place where they feel safe from violence and supported in their efforts to learn in English. These mediating factors, combined with influences reported in the Sociohistorical category, are uniformly positive and encourage the students to engage in school and school mathematics. The next three categories, however, report on other aspects of the children's lives that make engaging in school much more complicated endeavor.

\section{School Constraints: Structure, Language and Culture}

Math tracking. Valley Middle School places sixth graders who are underprepared in mathematics into General Math, which reviews elementary school concepts and skills. The other students are placed in grade level classes that prepare them for taking Algebra. Because sixth grade students in General Math do not learn the pre-algebra concepts that their fellow students are being taught, they don't catch up and most of them stay in General Math throughout middle school. When asked to discuss the General Math program and how it serves the students placed in it, the mathematics department head for the school stated the following:

Interviewer: Are you optimistic or pessimistic that this school can take students who come in underprepared for math and get them ready for algebra before they leave?

Larry: I'm ahhh.., very pessimistic. I would like to look at our records over the last five years and I would bet that at least $80 \%$ of the kids that come in below grade level in sixth grade... I bet its over $90 \%$, leave below grade level in eighth grade.

Approximately $75 \%$ of the Latino/a students at Valley Middle School were placed in General Math. Teachers realized that these classes did not serve the needs of the students placed in them, yet the school continued placing the majority of the Latino/a 
students in them. Math tracking has long been known not to prepare students for higher mathematics (e.g., Oakes, 2005; Slavin, 1993). The school was invested in helping these Latino/a students become English Language competent, but not in providing a math curricular structure that enabled them to succeed in the college prep curriculum the school provided.

In the interview with the parents, the school's math placement program was explained. It appeared that none of the parents knew about the tracking program and that their children were taking math classes that did not prepare them for college preparatory math in high school. Erica, the school counselor who translated and facilitated at the parent interview, stated the following afterwards:

Erica: One thing that I like to add. While we were showing this (a handout to explain the math tracking program), I wish you had a video camera, because I want you to remember the faces and the expressions of, "Ah my gosh, we did not know this before." There were a lot of wows, and you see a lot of rustling and movement in the back and a lot of them were kind of talking to each other and going, "Did you know that?" That was more body language and visual stuff than what they said. But I guarantee you that probably none of them knew about the tracking.

These parents were familiar with the single track math program that they encountered in schools in Mexico and believed that their children's passing grades in math indicated that they were making adequate progress.

Language problems. Despite the support they received from the school, the Latino/a students at Valley Middle School reported that language problems were one of the biggest issues that made school hard for them. In discussing their struggles, they described two ways that language made their classes hard: first, understanding the teachers and teachers' instructions and, second, being able to use English to complete assignments. The following two excerpts illustrate the understanding problems. Xavier, a seventh grade boy, talks about the "hard words" and his frustrations with not understanding in science class.

Interviewer: Why is science hard?

Xavier: Because um, it's a like about things that you don't know. And like they are wrong words and in tests at the beginning of the year, we got like a test of like words that we never got to learn like in sixth grade, and like I got a really low grade on it. Because they were hard words. And that was why it was hard.

Betty, a sixth grade girl, talks about the difficulty in following teacher instructions.

Interviewer: What makes science hard for you?

Betty: Sometimes when you are actually paying attention to the teacher... Sometimes she doesn't explain it good, so when you're done...like when she is done explaining it, you are like confused, cause you're like ah... Okay what should I do? And then she tells you to go ask someone else and then they probably didn't pay attention also... 
Xavier and Betty both reported goals for succeeding in school, but their limited vocabularies and lack of ability to quickly understand and interpret instructions in English impeded their progress towards school success. In the following excerpt three sixth grade boys discuss writing and completing assignments.

Interviewer: So what else is hard for Latinos in school?

Rafael: Like when you have to write, a big project like in English.

Interviewer: Is it hard because it is long and it is hard because it is in another language?

Rafael: Yeah.

Xavier: Like writing is hard... and reading and writing.

Interviewer: Would it be easier if you were writing it in Spanish?

Diego: Well I'm kind of speaking English more than I'm speaking Spanish.

Completing writing assignments and projects takes a long time for these students. Diego's comment describes the language dilemma of Subtractive Bilingualism (Valenzuela, 1999; Wright, Taylor, \& Macarthur, 2000). In Subtractive Bilingualism, the immigrant students' native language is gradually replaced by the dominant language. Completing assignments in English is hard for many of the Latino/a students at Valley Middle School because they are still learning the language. However, as they take classes in English, their academic skills and vocabulary in Spanish stop growing and decreases. They are caught in the middle between two languages and they are uncertain of their school skills in both English and Spanish.

European American school culture. Valley Middle School's programs and activities are a product of the European American culture of the community and are designed to serve the children from this dominant culture. Like many U.S. schools, Valley Middle School hopes that the Latino/a students can be served by being assimilated into the greater culture (Gandara \& Contreras, 2009; Garcia, 2009). This strategy for serving these students does not work and often alienates students from the school and the education they want and need (Bartolome, 1997; Delpit, 1992; Trueba, Bartolome, \& Macedo, 2000). The Latino/a students, coming from a different culture and experience, struggle to find their place in this European American school and ways to relate to the non-Latino/a students in the school. When asked about their non-Latino friends, Mateo and Ernesto (eighth graders) talked about their football team experiences:

Interviewer: Tell me about your non-Latino friends.

Mateo: So, the ones I talk to, they're all cool because... 'cause like this year when I got into my football team, like they all started knowing me and like I'm cool with them and everything. Last year, they all like, oh I'm not going to mess with you because you're Mexican, but now that they know me more, I talk to them and we, yeah...

Ernesto: Respect each other

Mateo: Yeah, we all respect each other. 
The football team provided what Lipka and his coauthors (Lipka et al., 2005) described as a third space - a space where cultures meet and dialog takes place. The football team at Valley Middle School is a "space" where students from Latino and non-Latino cultures can come together and bring the cultural backgrounds with them. The Latino students reported that joining the team allowed them to be known "as Mexicans," as who they are culturally, while participating fully on the team. Unfortunately, there are few "spaces" at Valley Middle School where this happens and often the students often feel alienated from their school.

\section{Community: Issues of Poverty}

Most of the Latino/a students at Valley Middle School come from families that live in poverty. In this section, students and parents discuss their economic situations at home and how their economic struggles get in the way of engaging in the school and school assignments.

No time for homework. In a discussion of what makes school hard, Yvette $\left(8^{\text {th }}\right.$ grader) talked about her family responsibilities when she gets home.

Interviewer: What would get in your way of being able to finish up all your homework?

Yvette: Taking care of my little brother.

Interviewer: Do you have to do that every day?

Yvette: Ah huh, after school, yeah.

Interviewer: And he won't just sit and play while you do your homework?

Yvette: No and then I have to do like the laundry and I have to making food, do the bed, and clean.

Yvette's responsibilities at home got in the way of her homework. Many of the Latino/a children at Valley Middle School come from families with many young children. Often both parents worked outside the home, cannot afford child care, and need their older children to take on many household and child care responsibilities.

Parents at work. In the parent interview, Alena anguished over how she did not have the time or school knowledge to help her children.

Alena: I am a divorced mother, I take care of my three children, and I work in the fields and I start at 6:30. So, I am not home and when I get home I am exhausted... I don't give them enough time. I didn't go to school. So I don't understand anything that they are working on.

Most of the parents in the study work at low paying, manual labor jobs in the agricultural, construction, or service industries. Often they have very little formal education, are unable to help their children with their homework, and do not understand the expectations and structure of schools in the United States. They want their children to succeed in school, but they don't know how to help them and, like many working parents, they come home tired from a long day of work. 
Supporting the family. In the excerpt below, Chiara (mother of two) talks about the effect the families' economic struggles have on their children's commitments to staying in school.

Chiara: In this country, the problem is that we don't have time. Time is short and it all has to do with our economic reality.... And the kids, I think a lot of them leave school, not because they don't want to study, but because they start seeing what the situation, the financial situation is at home, (and) they prefer to go to work. They feel the responsibility to help the parents financially because they realize that we just don't have enough to cover all the bills.

Living in poverty makes it harder for these Latino students to succeed in school. Their parents' beliefs in the value of education help the students set and work at goals for success in school. The same strong family ties, however, lead them to believe that helping their families is more important than their personal success in school.

\section{Prejudice and Institutional Bias: Fostering a Culture Apart}

In this section the Latino/a children and their parents discuss their individual experiences with prejudice and the laws and regulations of the institutions with which they interact. These experiences made them feel unwelcomed and unwanted in the United States and separated from the non-Latino community.

Prejudice. In talking about how success in school might affect his life, Fidel stated the following:

\section{Interviewer: What would happen if you got straight A's?}

Fidel: It would change the stereotype of people when they think of Mexicans that they are dumb.

Fidel was not asked about prejudice or discrimination, but by making it part of his answer, he demonstrated how prejudice had informed his experience in the United States. In the following excerpt, two parents discuss their experiences with prejudice in the community and their perceptions about the attitudes of some people:

Lena: I work at a nursing home and there is a person there who has made my work difficult. She is always saying that the Latinos are here to create problems and...thinks that all Latinos are here to take advantage of welfare.... I am trying to explain that to her that not all of us are here trying to take advantage of the system. But there are people that will never change their minds.

Pedro: The reality is that when somebody is against the Latin community, that they will always look at our defects and focus and pay attention on our defects instead of our qualities.

All of the student groups and their parents reported that prejudice and discrimination was part of their experience of being in the United States. When asked about making changes to their school, the seventh and eighth grade boys said the following:

Interviewer: If you could make changes in the school, what would you change?

Carlos: All the racist kids. 
Interviewer: You feel that there are racist kids at the school.

Carlos: Yes.

Interviewer: How does it happen? How can you tell that people are racist?

Carlos: Because they say to Mexicans, "Go pick some fruit or do my garden." They say that sometimes.

Amos: It's actually true. I have heard that before.

Mateo: Umm, people, I have seen people that just because you're one color, they think you are like one level behind them.

Instances of racism and prejudice lead to a wariness among the Latino students in the ways they relate to non-Latino students and causes them to pull together and not readily engage in the larger student community at the school.

Barriers to college. The local community colleges and state universities have adopted a "don't ask" policy for admitting students without documentation. Students who graduate from a local high school are considered residents of the state, and no further questions are asked about their immigration status. Undocumented college students, however, cannot receive scholarships or financial aid because that is controlled by federal agencies that require documentation. Theresa, a Latina college student who came to the parent meeting and discussed how her teachers had helped her prepare for college, has no documentation. Her situation is described by the school counselor in the excerpt below:

Erica: I know she (Theresa) doesn't have papers. I know she is working. She is working very hard. She is working 30 hours a week and is taking a full load [of courses at college]. And she is living at home in town and driving to school [in the next town] every day... She cannot afford the dorms... So, she comes from school, she goes to work until the restaurant closes, and goes home and goes back to school in the morning.

Going to college requires many hours of hard work and is a substantial expense for the students and their families. It is hard for students coming out of a life of poverty, imbued with an ethic that children help their families, to justify spending so much energy and income on their college education. Alena (parent of two) does not see much point in her children preparing for college:

Alena: In the case of my kids, since they are not from here, when they finish high school what can they do? I have been telling them, just get yourself ready to go to work.

"Taking us away." Students and parents reported that they continually worry that immigration agents will take them or members of their families away. When asked about immigration, Mateo, the eighth grader who discussed his participation on the football team, talked about his constant worries about his mother:

Interviewer: Do you think the school might report Latinos to immigration?

Mateo: I don't know ... I'm ... a little afraid at school, but I am also afraid of if I get to my house and then I don't see my Mom coming and I'll probably think that 
they took her... like I'm always in class and think about if my Mom is at work or she's like... they've taken her somewhere.

The parents reported that their greatest worry was not for themselves, but for their children.

Chiara: The fear is not that they are going to send us back. Because we go back and then all laugh and say that we'll just cross again.

Alena: The big fear is what if the kids stay and you are the one deported and that you know that your kids don't have anybody to take care for them. What's going to happen? How are they going to survive? What's going to happen to them? ... Now people are talking that they are coming to work, so when I am at work I start planning which way am I going to run.

The fear of immigration and the separation from their families and friends is a constant stressor among the Latino students Valley Middle School. It sets them apart from the other students in the school and keeps them in the shadows of the community.

We do not belong - No membership card. In the interviews, the students talked repeatedly about their immigration status and whether or not they had the "card" (meaning a social security card) or "papers" that gave them legal status in the United States. In the following excerpt, Salina, a sixth grader, discusses her immigration status and her family's expectations for her to succeed in school:

Salina: Well like what my Mom wants is that.., she wants me to finish school. In my family, I am the only one that has papers. So my Mom says that I can't be wasting what other people want.

The family expectations held for Salina demonstrate how immigration status affects the way Latino families think about the opportunities that are available to their children. Salina is seen as having an opportunity to succeed. Children without "cards or papers" belong to the class of Latinos for whom education provides much less promise of success. These students see "cards and papers" as what certifies people as belonging in the United States. About half of them have no documentation and feel that without "cards or papers" it is much more difficult for them to fully participate and succeed in the United States. In the following excerpt, Lena, a parent, summed up her feelings about the situation that she had placed her children in by bringing them to the United States:

Interviewer: What has been hard for your child?

Lena: The fact of being Hispanic and the fact that we moved them from a country where we belong. So they feel rejected because they don't have legal papers... And even if the school is giving them the support, they don't feel that they can get as far as the rest.

Lena's summation of her children's troubles reflects much of what the students and parents consistently presented in these interviews about their experiences in the United States. The students identify themselves as Mexicans. They are blocked by their ethnicity and their undocumented status from becoming part of the United States, and they see themselves as people separated and apart from many of the advantages and opportunities in the country. 


\section{Summary of Influences on Engagement in School}

This research set out to address the question:

How do sociohistorical backgrounds, community forces and school structure and culture mediate Latino/a students' motivation and engagement in school and school mathematics?

This question grew out of the model used by Martin (2000) to interpret how sociohistorical, community, and school factors influence African American student engagement with mathematics in middle school. As the Voces Project research progressed, this model was expanded to include School Affordances and Constraints, and a new category, Prejudice and Institutional Bias. So the question this research came to address is:

How do Sociohistorical Backgrounds, Community Forces, School Affordances and Constraints, and Prejudice and Institutional Bias mediate Latino/a students' motivation and engagement in school and school mathematics?

The analysis of the Voces Model using student beliefs, goals, and interests shows that many factors mediate against the students' positive engagement in school and school mathematics. "Mediate" is used here to indicate that the factors described in this study do not control, but rather influence, the students' motivation to engage in school. These factors make up the context in which the students operate. As noted above, the students' sociohistorical backgrounds predispose them to developing positive beliefs, goals and interests towards school. Valley Middle School's support of these students, in part, provides an environment where they can successfully engage in school. The influences of poverty, school structure and culture, and prejudice and institutional bias, however, all mediate against these students finding ways to make sense of positively engaging in school. The support the school provides, and the "hearts" of the students, must be very strong to overcome the other influences that make it hard for them to engage in school and school mathematics.

\section{Conclusion: Implications for Research and Schools}

This research reports on the multiple mediating factors that affected the lives of Latino/a children at Valley Middle School and presents a model for understanding and explaining how these children made sense of engaging in school and school mathematics. Other research conducted in U.S. schools that primarily serve large Hispanic populations found many similar factors influencing student engagement (e.g., Civil, 1998; Gonzalez, et al., 2005; Gutierrez, 2002a; Gutstein, 2006). This study complements this prior research, and the Voces Model presents an explanation of how Latino/a children who are part of minority student population make sense of engaging in school and school mathematics.

This research also complements work done in other regions of the world. Vedder, Horeneczyk and Liebkind (2006), in their paper on the ethno-cultural 
challenges facing European schools, noted that language issues, prejudice, and alienation caused many immigrant children not to engage in school. Reitz (2005) reported that structural inequality and prejudice kept immigrant populations in Canada from prospering economically despite a willingness to engage in school. The Voces Model may be a useful lens for researchers in these countries to use in analyzing the impact of education structures on immigrant children's engagement in school. The Model's five-category framework (Sociohistorical, Community, School Affordances, School Constraints, and Prejudice and Institutional Bias) provides an organizational structure for understanding and explaining how students make sense of engaging in school and school mathematics (Figure 3). Other schools and communities will likely have different sets of mediating factors. The Voces Model framework, however, may prove useful in building a structure and model for explaining how students in other schools and other regions of the world make sense of engaging in school.

Figure 3. The Voces Model Framework. Depicting the categories of factors that mediate how Latino/a middle school students make sense of engaging in school and school mathematics.

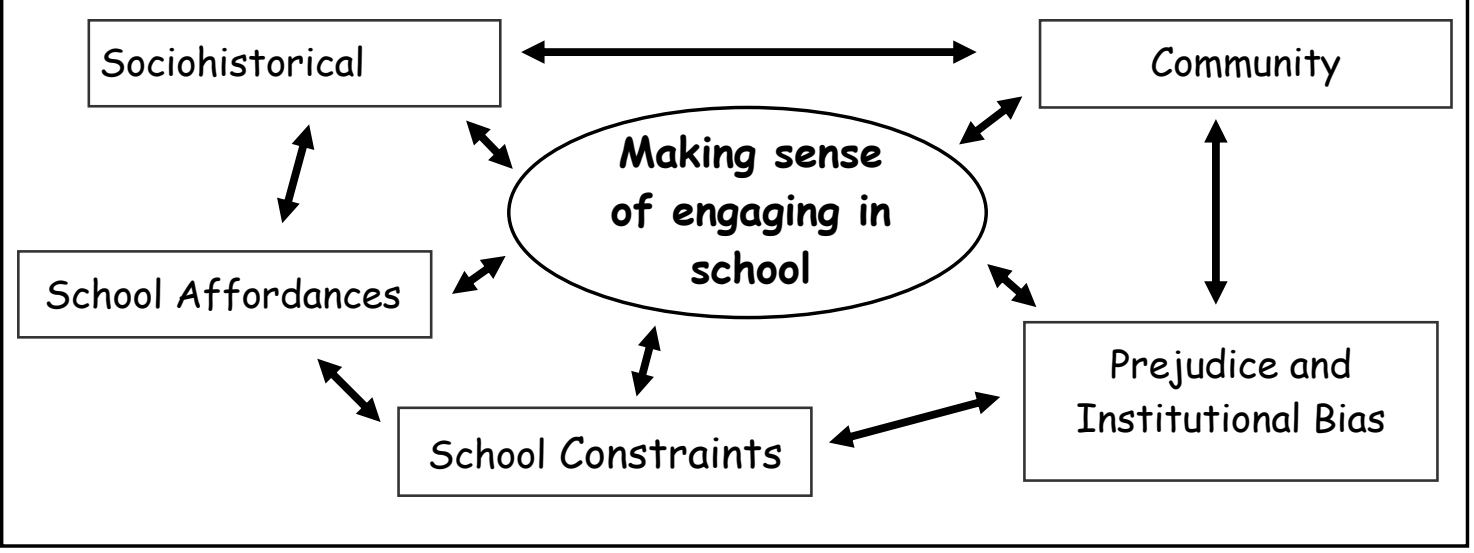

Oscar asserted that "heart" would be enough for him to succeed in school. The Voces Model predicts that there will be many obstacles in Oscar's path to school success and that these obstacles will test his heart and the hearts and the "Sí, se Puede" attitudes of his Latino/a classmates. By describing the multiple factors that influence how Latino/a students make sense of engaging in school, this research provides insights into the types of programs and government changes that are needed to help more students like Oscar succeed in school. Schools need to continue language support programs (Gandara \& Contreras, 2009; Garcia, 2009) and to work at providing more "third spaces" where immigrant students feel accepted and welcomed (Lipka, et al., 2005). All of us need to be intolerant of prejudice and assert that it has no place in our schools and communities. And if we truly want to welcome hard working immigrant families into our communities, we will implement school and immigration policies that reward children for engaging in school and provide a path to prosperity that includes them as full members of their new country's culture and society. 


\section{Notes}

1. The name of the school, city, and the names of the participants in this article are pseudonyms.

\section{References}

Bandura, A. (1997). Self-efficacy: The exercise of control. New York, NY: W. H. Freeman \& Co.

Bartolome, L. (1997). Dancing with bigotry: The poisoning of racial and ethnic identities. Harvard Educational Review, 67(2), 222-246.

Boaler, J. (1999). Participation, knowledge, and beliefs: A community perspective on mathematics learning. Educational Studies in Mathematics, 40(3), 259-281.

Boaler, J. (2000). Mathematics from another world: Traditional communities and the alienation of learners. Journal of Mathematical Behavior, 18(4), 1-19.

Charmaz, K. (2006). Constructing grounded theory: A practical guided through qualitative analysis. London, UK: Sage.

Civil, M. (1998). Bridging in-school and out-of-school mathematics: A reflection. Paper presented at the Annual Meeting of the American Educational Research Association, San Diego, CA.

Cobb, P. (1994). Where is the mind? Constructivist and sociocultural perspectives on mathematical development. Educational Researcher, 23(7), 13-20.

Covington, M. V. (1992). Making the grade. Cambridge: Cambridge University Press.

Deci, E. L., \& Ryan, R. M. (2002). Handbook of self-determination research. Rochester, NY: Univeristy of Rochester Press.

Delpit, L. D. (1992). Education in a multicultural society: Our future's greatest challenge. Journal of Negro Education, 61(3), 237-249.

Dewey, J. (1913). Interest and Effort in Education. Boston, MA: University Press.

Donovan, M. S., \& Bransford, J. S. (Eds.). (2005). How students learn: Mathematics in the classroom. Washington, D. C.: National Academies Press.

Eccles, J. S., \& Wigfield, A. (2002). Motivational beliefs, values, and goals. Annual Review of Psychology, 53, 109-132.

Gandara, P. C., \& Contreras, F. (2009). The Latino education crisis: The consequences of failed social policies Cambridge, MA: Harvard University Press.

Garcia, O. (2009). Bilingual education in the 21st century: A global perspective. Oxford, UK: Wiley and sons.

Gonzalez, N., Moll, L., \& Amanti, C. (Eds.). (2005). Funds of knowledge: Theorizing practice in households, communities, and classrooms. . Mahwah, NJ: Lawrence Erlbaum. 
Gutierrez, R. (2002a). Beyond essentialism: The complexity of language in teaching mathematics to Latino/a students. American Educational Research Journal, 39(4), 1047-1088.

Gutierrez, R. (2002b). Enabling the practice of mathematics teachers in context: Toward a new equity research agenda. Mathematical Thinking and Learning, 4(2\&3), 145-187.

Gutstein, E. (2006). "The real world as we have seen it": Latino/a parents' voices on teaching mathematics for social justice. Mathematical Thinking and Learning, 8(3), 331-358.

Gutstein, E., Lipman, P., Hernandez, P., \& de los Reyes, R. (1997). Culturally relevant mathematics teaching in a Mexican American context. Journal for Research in Mathematics Education, 28(6), 709-736.

Hickey, D. T., \& Granade, J. B. (2004). The influence of sociocultural theory on our theories of engagement and motivation. In D. M. Mclnerney \& S. Van Etten (Eds.), Big theories revisited (pp. 223-247). Greenwich, CT: Information Age Publishing.

Knudson-Martin, J. (2011). A combined model for understanding motivation. International Journal of Contemporary Research, , 1(2)(2), 11-16.

Lipka, J., Hogan, M. P., Webster, J. P., Yanez, E., Adams, B., Clark, S., \& Lacey, D. (2005). Math in a cultural context: Two case studies of a successful culturally based math project. Anthropology and Education Quarterly, 36(4), 367-385.

Maehr, M. L. (1984). Meaning and motivation: Toward a theory of personal investment. In C. Ames \& R. Ames (Eds.), Research on Motivation in Education: Student Motivation (pp. 115-144). Orlando, FL: Academic Press.

Martin, D. B. (2000). Mathematics success and failure among African-American youth: The roles of Sociohistorical context, community forces, school influence, and individual agency. Mahwah, NJ: Lawrence Erlbaum Associates.

Moll, L. C. (1997). The creation of mediating settings. Mind, Culture and Activity, 4(3), 191-199.

Murphy, P. K., \& Alexander, P. A. (2000). A motivated exploration of motivation terminology. Contemporary Educational Psychology, 25, 3-52.

Oakes, J. (2005). Keeping track: How schools structure inequality (2nd ed.). New Haven, CT: Yale University Press.

Pajares, F., \& Graham, L. (1999). Self-efficacy, motivation contructs and mathematics performance of entering middle school students. Contemporary Educational Psychology, 24, 124-139.

Reitz, J. G. (2005). Diversity, equality, and the cohesion of Canadian society: Research findings and policy implications. Paper presented at the Diversity and Canada's Future: Recognition, Accommodation and Shared Citizenship," organized by the Institute for Research on Public Policy, Montebello, Quebec. 
Slavin, R. E. (1993). Students differ: So what? Educational Researcher, 22(9), 13-14.

Trueba, E. T., Bartolome, L. I., \& Macedo, D. (Eds.). (2000). Immigrant voices: In search of educational equity. New York, NY: Rowman \& Littlefield.

Valadez, j. R. (2008). Shaping the educational decisions of Mexican immigrant high school students. American Educational Research Journal, 45(4), 834-860.

Valenzuela, A. (1999). Subtractive schooling: U.S.-Mexican youth and the politics of caring. Albany, NY: State University of New York Press.

Vedder, P., Horenczyk, G., \& Liebkind, K. (2006). Ethni-culturally diverse education settings; Problems, challenges and solutions. Educational Research Review, 1(2), 157-168.

Vygotsky, L. S. (1986). Thought and Language. Cambridge, MA: MIT Press.

Wertsch, J. V., \& Toma, C. (1995). Discourse and Learning in the classroom: A sociocultural approach. In L. P. Steffe \& J. Gale (Eds.), Constructivism in Education (pp. 159-174). Hillsdale, NJ: Lawrence Erlbaum Associates.

Wright, S. C., Taylor, D. M., \& Macarthur, J. (2000). Subtractive bilingualism and the survival of the Inuit language: Heritage-versus second language education. Journal of Educational Psychology, 92(1), 63-84.

Zimmerman, B. J., Bandura, A., \& Martinez-Pons, M. (1992). Self-motivation for academic attainment: The role of self-efficacy beliefs and personal goal setting. American Educational Research Journal, 29(3), 663-676. 